\section{Modality of similarity and hearing ability*}

\author{
DORIS V. ALLEN
}

Department of Audiology, Wayne State University, Detroit, Mich. 48202

Paired-associate lists differing in implicit modality of cue (auditory or visual) and in response mode (written or oral) were learned by five groups of children differing in hearing ability (normal to deaf). Overall, visual cues were easier than auditory cues, but cues interacted with hearing ability such that implicit auditory cues (rhymes) contributed less to the performance of Ss with impaired hearing.

Early severe hearing impairment manifests itself primarily in later retarded language skills. This relationship is generally taken to mean that loss in hearing ability interferes quantitatively with the development of language. That is, the language of the hearing-impaired is regarded as representing some less well-developed immature stage of verbal functioning through which all persons pass.

In contrast to this quantitative view, a qualitative explanation should be explored. An early hearing loss may alter the perception, so that primary emphasis is placed upon sense modalities other than audition as information-gathering channels. Thus, the dimensions underlying cognitive processes might be visual-tactile rather than auditory-visual, which probably best describes the process in normal-hearing individuals. Numerous studies of short-term memory (e.g., Conrad, 1964; Wickelgren, 1965) suggest that the hearing person transforms written verbal material to its auditory equivalents during storage and retrieval. This transformation probably reflects the fact that oral language precedes the written mode in time. If this is so, the hearing-handicapped person would not be expected to make the same kind of transformation, since oral language is not as "basic" to him, generally being acquired later in life. It is for this reason that qualitatively different strategies in processing verbal material are expected as a function of hearing ability.

Conrad \& Rush (1965) provide evidence supporting qualitative differences as a function of hearing ability in their study of short-term memory in the deaf. They found that deaf and normals differed in the manner in which they stored letters of the alphabet; normals apparently used auditory encoding, while the deaf did not. The fact that errors were consistent among the deaf led Conrad

* The work reported herein was performed pursuant to Grant No. OEG-0-8-07837-1858 from the U.S. Office of Education. Department of Health, Education, and Welfare. and Rush to conclude further that some other encoding system was being used which they were unable to identify. Similarly, Odom \& Blanton (1967) varied word order in phrases and found that recall by normal Ss was adversely affected by unusual word orders, while recall by the deaf was not affected by this factor. They suggested that the linguistic structure of sign might be more important for understanding how the deaf learn word phrases. Pronunciability of trigrams presented for recognition (Blanton \& Nunnally, 1967) or for recall (Blanton \& Odom, 1968) has been studied using normal and deaf Ss. In both instances, the deaf were unaffected by the pronunciability ratings, while normal-hearing Ss showed a deterioration in performance for the items rated more difficult to pronounce. Allen (1970) used acoustic similarity to produce interference in a paired-associate task and reported a positive relationship between amount of hearing loss and resistance to interference. The deaf also exhibit less interference on the color-word task of the Stroop test than do normals (Allen, 1971). Thus, a number of studies suggest that hearing-impaired Ss do not handle verbal material internally in the same fashion as do normals.

Unpublished Research by McLinden (1959) gives additional support for qualitative differences in learning as a function of hearing. She provided auditory or visual cues for learning

Table 1

Mean Trials to Criterion (TTC) and Standard Deviations (SD) in Four Experimental Conditions for Five Hearing Categories

\begin{tabular}{|c|c|c|c|c|c|c|}
\hline $\begin{array}{l}\text { Hearing } \\
\text { Category }\end{array}$ & $\mathbf{N}$ & & OA & OV & WA & WV \\
\hline Normal & 13 & $\begin{array}{l}\text { TTC } \\
\text { SD }\end{array}$ & $\begin{array}{l}4.77 \\
1.74\end{array}$ & $\begin{array}{l}4.92 \\
2.84\end{array}$ & $\begin{array}{l}4.69 \\
1.97\end{array}$ & $\begin{array}{l}4.15 \\
1.68\end{array}$ \\
\hline $0-25$ & 7 & $\begin{array}{l}\text { TTC } \\
\text { SD }\end{array}$ & $\begin{array}{l}8.14 \\
3.02\end{array}$ & $\begin{array}{l}3.57 \\
1.14\end{array}$ & $\begin{array}{l}7.29 \\
4.82\end{array}$ & $\begin{array}{l}4.43 \\
1.27\end{array}$ \\
\hline $26-60$ & 8 & $\begin{array}{l}\text { TTC } \\
\text { SD }\end{array}$ & $\begin{array}{l}6.38 \\
2.93\end{array}$ & $\begin{array}{l}4.75 \\
2.25\end{array}$ & $\begin{array}{l}5.50 \\
2.33\end{array}$ & $\begin{array}{l}4.13 \\
2.17\end{array}$ \\
\hline $61-90$ & 8 & $\begin{array}{l}\text { TTC } \\
\text { SD }\end{array}$ & $\begin{array}{l}5.50 \\
1.31\end{array}$ & $\begin{array}{l}3.63 \\
1.30\end{array}$ & $\begin{array}{l}5.63 \\
3.11\end{array}$ & $\begin{array}{l}3.75 \\
1.49\end{array}$ \\
\hline $91+$ & 9 & $\begin{array}{l}\text { TTC } \\
\text { SD }\end{array}$ & $\begin{array}{l}7.00 \\
2.55\end{array}$ & $\begin{array}{l}3.56 \\
1.60\end{array}$ & $\begin{array}{l}6.11 \\
1.69\end{array}$ & $\begin{array}{l}3.44 \\
1.60\end{array}$ \\
\hline
\end{tabular}

printed word pairs and found that printed word pairs which sounded alike (ROUGH-CUFF) were easier for normal-hearing children to learn, while printed word pairs which looked alike (LOST-MOST) were easier for hearing-loss Ss. However, all of her Ss responded orally, a fact which could explain the performance of the normals. Speaking the answers might encourage the use of acoustic attributes for storage, since the information would be retained in the form needed for responding. While this explanation for her findings is possible, it is weakened by the fact that the short-term memory studies demonstrating acoustic encoding have generally employed written responses. Thus, acoustic memory seems to be characteristic of normal-hearing Ss regardless of response mode. It is predicted that performance in McLinden's study would not be different if written response modes were used.

The present study was designed to confirm the findings of McLinden regarding an interaction between nature of cue and hearing ability and to examine the effects of a written response mode upon performance. While a significant interaction between hearing ability and modality of cues was expected, no interaction between modality of cues and response mode was predicted.

\section{MATERIAIS}

The materials consisted of two lists of eight word pairs which rhyme but are spelled differently (auditory lists), two lists of eight word pairs which are spelled similarly but differ in pronunciation (visual lists), and a list of four unrelated word pairs (practice list). An example of an auditory pair would be SIGN-LINE, while CAVE-HAVE would be a visual pair. All words were rated $A$ or $A A$ in frequency (Thorndike \& Lorge, 1944) and were monosyllabic.

SUBJECTS

A total of 45 children were tested. Five groups were established on the 


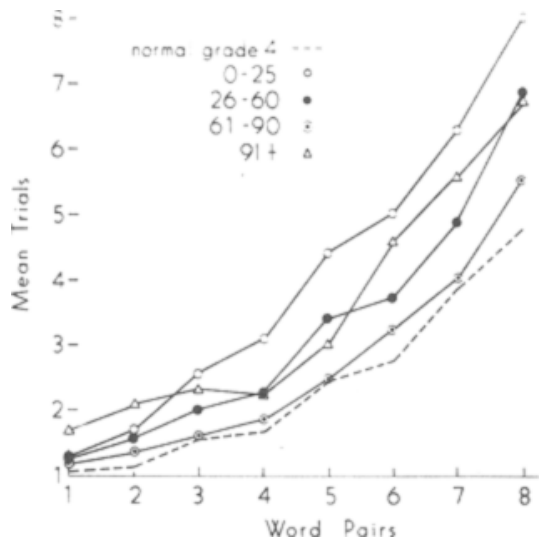

Fig. 1. Learning curves for five categories of hearing ability for Condition OA.

basis of hearing ability, using the average pure-tone threshold for 500 , 1,000 , and $2,000 \mathrm{~Hz}$ in the better ear. One group had normal hearing, while four had some degree of sensorineural hearing impairment: $0-25 \mathrm{~dB}$ ISO (mild or nonsignificant losses), 26-60 dB (moderate losses or "hard of hearing"), 61-90 dB (severe losses), and $91+\mathrm{dB}$ (profound losses or "deaf"). In addition, all Ss were required to have grade-equivalent reading scores of 3.5 to 6.0 (Iowa Test of Basic Skills).

\section{PROCEDURE}

Visual presentation was used for all conditions. A Tel-n-See film-strip projector (with an inbuilt synchronized tape recorder) and a lenticular screen were used; letter height in the projected image was 8 in. The materials were photographed on $16-\mathrm{mm}$ film strips in reverse image; 2-sec presentation intervals were controlled by tape-recorded signals.

One each of the auditory and visual lists was assigned to a written response condition, the other to an oral; the combination changed for each child. In this manner, four experimental conditions were formed: oral auditory (OA), oral visual (OV), written auditory (WA), and written visual (WV). Order of administration of the four lists was counterbalanced, and each $\mathrm{S}$ was assigned to an order at the first session.

Initially, the practice list was administered in the same response mode as the first test list; for example, if the first test condition was to use written responses, practice was also written. Practice continued until the $S$ understood the task. Usually only a few trials were needed. This was followed by the first test list; alternate study and test trials were administered until the $S$ achieved one errorless trial. Booklets with separate pages for each trial were used for written responses, and a cassette tape recorder was used during oral responding. The remaining three lists were administered at separate sessions. At no time was attention directed to the relevant dimension for the cues; each subsequent session was begun with a statement to the effect that another list of word pairs was to be learned, and the response mode was defined.

\section{RESULTS}

The mean number of trials to a criterion of one errorless trial for the five groups and the four experimental conditions are summarized in Table 1. As shown there, the auditory lists were more difficult than the visual for all the hearing-loss groups but not for normal-hearing Ss, while the groups all performed alike on the visual lists. Modality of response apparently did not contribute differentially to learning. These trends were supported statistically. The only significant sources of variance were cues $[F(1,40)=28.40, p<.01]$ and Cues by Hearing Ability interaction $[F(4,40=3.44, p<.05]$. A posteriori tests using the Scheffé procedure (Winer, 1962) showed the $0-25 \mathrm{~dB}$ group to be significantly poorer, as compared with normals, on the auditory lists. None of the differences among groups for the visual lists was significant. Simple effects for cues showed that visual cues were significantly easier for the $0-25 \mathrm{~dB}$ and $91+\mathrm{dB}$ hearing-loss groups.

Learning curves for the groups for each condition were also examined, with points representing mean number of trials needed to learn the first word pair (regardless of which pair it was), the second pair, etc. The curves for the two auditory conditions, OA and WA, were much alike, as were the curves obtained for the two visual conditions, OV and WV; only one of each set is presented here. The learning curves for both auditory conditions showed a marked spread among the five groups, as illustrated by Fig. I (Condition OA). The poorest performance on practically all auditory pairs was shown by the 0-25 $\mathrm{dB}$ group, while the normal-hearing group showed the best performance. These data are in marked contrast to the two visual conditions. As seen in Fig. 2 (Condition OV), there is little spread among the curves for the groups. The normal group was now the slowest, with the deaf group fastest in acquiring each visual pair. Since repeated measurements were used, differences must be attributed to materials and not to sampling differences. Also, order of presentation of the lists had been counterbalanced to offset any bias due to sequencing effects.

Since the groups were controlled on reading ability, they necessarily differed in age. To evaluate whether or not this variable contributed to the obtained differences, correlations between age and performance were calculated for the 32 Ss with impaired hearing. These values ranged in magnitude from .03 to -.12 for the four conditions and were not significant.

\section{DISCUSSION}

The two hypotheses in this study were supported by the data. The fact that we failed to reject the null hypothesis for the interaction between modality of cues and response mode is interpreted as indicating that no such practical relationship exists, fully recognizing the philosophical problems inherent in such a conclusion. Greater confidence in this interpretation is obtained from the very small $F$ ratio for this source of variance. As for the other hypothesis in this study, a significant Cues by Hearing Ability interaction was obtained, with differences somewhat in the predicted direction, i.e., the visual material was learned more rapidly than the auditory by the hearing-impaired, while normal Ss learned all lists at the same time. These data are consistent with the results obtained by McLinden, who also found a significant interaction between cues and hearing ability, and reinforce the theory that a congenital hearing loss results in different strategies' being used in learning verbal materials.

Since cues for learning word pairs are constant within a list, it might be suspected that differences in trials to criterion merely reflect differences in the trials needed to recognize the relevant dimension. If this were so, then the learning curves should show the groups to be separated on the number of trials needed to learn the first pair and should be negatively accelerated thereafter. In fact, just the opposite was observed. The groups did not differ in trials to acquire the first item but did diverge on subsequent

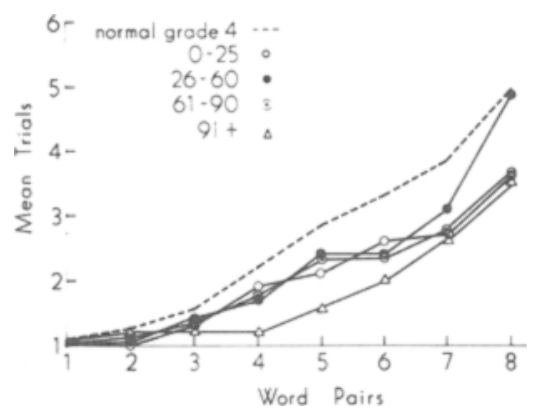

Fig. 2. Learning curves for five categories of hearing ability for Condition OV. 
pairs with more trials needed to learn successive pairs. In particular, the curves for the 0-25 dB group with Conditions $O A$ and WA suggest a laborious trial-by-trial acquisition of materials similar to what one might see with unrelated word pairs. Thus, the learning-curve data serve to demonstrate further the hypothesized qualitative differences in approach to verbal material by hearing and hearing-impaired children.

The fact that the $0-25 \mathrm{~dB}$ group showed the greatest effect of modality of cues is intriguing. This group is usually considered to be most like normal-hearing Ss yet performed least like the normal group in this study. Possibly auditory training, generally recommended for more severe losses, could be of benefit to these Ss also. Obviously, further research with hearing losses of this magnitude is needed.

\section{REFERENCES}

ALLEN, D. V. Acoustic interference in paired-associate learning as a function of hearing ability. Psychonomic Science, $1970,18,231-233$.

ALLEN, D. V. Color-word interference in deaf and normal children. Paper presented at $43 \mathrm{rd}$ annual meeting of
Midwestern Psychological Association. Detroit, Michigan, May 1971.

BLANTON, R. L., \& NUNNALLY, J, C Retention of trigrams by deaf and hearing subjects as a function of pronunciability. Journal of Verbal Learning \& Verbal Behavior, 1967, 6, 428-431.

BLANTON, R L \& ODOM, P B Some possible interference and facilitation effects of pronunciability. Journal of Verbal Learning \& Verbal Behavior, $1968,7,844-846$.

CONRAD, R. Acoustic confusions in immediate memory. British Journal of Psychology, 1964, 55, 75-84.

CONRAD, R., \& RUSH, M. L. On the nature of short-term memory encoding by the deaf. Journal of Speech \& Hearing Disorders, 1965, 30, 336-343.

McLINDEN, M. M. C. Learning with different associative cues by normal-hearing and hearing-impaired children. Unpublished data, Wayne State University, 1959.

ODOM, P. B., \& BLANTON, R. L. Phrase-learning in deaf and hearing subjects. Journal of Speech \& Hearing Research, 1967, 10, 600-605

THORNDIKE, E. L., \& LORGE, I. The teacher's word book of 30,000 words. New York: Bureau of Publications, Teachers College, Columbia University, 1944.

WICKELGREN, W. A. Acoustic similarity and intrusion errors in short-term memory. Journal of Experimental Psychology, 1965, 70, 102-108.

WINER, B. J. Statistical principles in experimental design. New York: McGraw-Hill, 1962.

\title{
Judgment of temporal duration as a function of numerosity
}

\author{
SUCHOON S. MO \\ University of Detroit, Detroit, Mich. 48221
}

In judging brief stimulus duration, change of the number of dark dots from three to one resulted in underestimation, while similar change from three to five resulted in overestimation. Such a trend of temporal judgment was accentuated when the change was less frequent, demonstrating a contrast effect. But the analogous contrast effect was also obtained when the stimulus duration itself was changed.

Several studies reviewed and discussed by Fraisse (1963) show that temporal estimation is an increasing function of such stimulus attributes as intensity, frequency, extensiveness, and complexity. Two tentative explanations were advanced by Fraisse. One is that such attributes may influence the adaptation level by functioning as contextual stimuli. The explanation is the one used in a study by Hirsch, Bilger, \& Deatherage (1956) to account for overreproduction of temporal duration brought about by the presence of an auditory contextual stimulus. The other explanation is based on the assumption that there is a monotonic relation between the level of attention and temporal estimation so that a more intense stimulus, for example, may lead to overestimation of its duration because it is more attention-provoking (Fraisse, 1963, pp. 134-135).
Suppose that unexpected change in either a stimulus attribute or the duration itself is introduced into the experiment. Then these two explanations are incompatible, at least conceptually, with each other. With regard to the adaptation level, such a change should bring about a contrast effect in temporal estimation. On the other hand, if overestimation is due to the level of attention, then such change should bring about overestimation of duration, never underestimation. This study tests and investigates this incompatibility.

\section{EXPERIMENT 1}

Subjects

Fifteen male and 5 female undergraduates from the introductory psychology courses were assigned to two groups, G1 and G2, of 10 Ss each. Apparatus

Each stimulus was a $4 \times 5$ in. white card bearing either one, three, or five dark dots. These dots were distributed randomly on each card by means of a nine-cell rectangular grid measuring $3 \times 3 \mathrm{~cm}$. Assignment of dots over this grid was done by using two-digit random numbers. Altogether there were 30 cards, each set of 10 cards bearing one $\left(N_{1}\right)$, three $\left(N_{3}\right)$, or five $\left(\mathrm{N}_{5}\right)$ dots. Presentation of each stimulus card was conducted binocularly with a Lafayette U-1 electronic tachistoscope. Procedure

Each S was told that there were two durations, one short and one long, and that the task was to identify and report verbally in each trial which duration was presented, short or long. These two durations were .30 and .33 sec. Following 10 practice trials, 60 trials altogether were administered in such a way that for Ss in $G 1$, the probabilities of distribution of $N_{1}, N_{3}$, and $\mathrm{N}_{5}$ were all .33 , and for $\mathrm{Ss}$ in $\mathrm{G2}$, they were $.17, .66$, and .17 , respectively. As to the duration, the probabilities of both short and long durations were $\mathbf{5 0}$. The intertrial interval was about .5 min. Throughout the entire trials, Ss were not allowed to detach their faces from the eyepiece in order to ensure a uniform light adaptation. At the end of the experiment, each $S$ was asked how many dots he saw. No $S$ failed to judge correctly the number of dots.

Results and Discussion

The proportions of the "long" responses as a function of the number of dots are presented in Fig. 1. Using the arcsin transforms, an analysis of variance was conducted. Its results indicate that the increasing trend of such "long" judgments as a function of the number of dots is significant $(\mathrm{F}=11.22, \quad \mathrm{p}<.005)$. Also, it is observed that this trend is more pronounced in G2 than in G1, 